\title{
Dose-Related Effects of Chronic Antidepressants on Neuroprotective Proteins BDNF, Bcl-2 and Cu/Zn-SOD in Rat Hippocampus
}

\author{
Haiyun $\mathrm{Xu}^{\prime}$, J Steven Richardson ${ }^{1,2}$ and Xin-Min Li*, \\ 'Neuropsychiatric Research Unit, Department of Psychiatry, and ${ }^{2}$ Department of Pharmacology, College of Medicine, University of \\ Saskatchewan, Saskatoon, Saskatchewan, Canada
}

\begin{abstract}
It has been proposed that antidepressants have neuroprotective effects on hippocampal neurons. To further test this hypothesis, brainderived neurotrophic factor (BDNF), B cell lymphoma protein-2 (Bcl-2), and copper-zinc superoxide dismutase (Cu/Zn-SOD) were examined immunohistochemically in hippocampal neurons of Sprague-Dawley rats following daily treatment with 5 or $10 \mathrm{mg} / \mathrm{kg}$ of amitriptyline or venlafaxine for 21 days. At $5 \mathrm{mg} / \mathrm{kg}$, both amitriptyline and venlafaxine increased the intensity of BDNF immunostaining in hippocampal pyramidal neurons, and the intensity of Bcl-2 immunostaining in hippocampal mossy fibers, but did not alter the Cu/ZnSOD immunoreactivity. The high dose of venlafaxine, however, decreased the intensity of BDNF immunostaining in all subareas of the hippocampus and increased the intensity of Cu/Zn-SOD immunostaining in the dentate granular cell layer. The high dose of amitriptyline increased the intensity of $\mathrm{Cu} / \mathrm{Zn}-\mathrm{SOD}$ immunostaining, but did not affect the immunoreactivity of Bcl-2 or BDNF. These findings suggest that the chronic administration of amitriptyline or venlafaxine at $5 \mathrm{mg} / \mathrm{kg}$, but not $10 \mathrm{mg} / \mathrm{kg}$, may be neuroprotective to hippocampal neurons. These dose-related effects of antidepressant drugs on hippocampal neurons may have relevance to disparate findings in the field.

Neuropsychopharmacology (2003) 28, 53-62. doi: I 0.1038/sj.npp. 1300009
\end{abstract}

Keywords: antidepressants; Bcl-2; BDNF; Cu/Zn-SOD; hippocampus; immunohistochemistry

\section{INTRODUCTION}

Although antidepressant drugs have been effectively used in the treatment of depression for more than 40 years, the mechanism responsible for their therapeutic action has not yet been fully explained. The initial hypothesis for the action of antidepressants (the so-called monoamine hypothesis: Bunney and Davis, 1965; Schildkraut, 1965) was based mainly on the elevation of brain levels of noradrenaline and serotonin produced by the early tricyclic and monoamine oxidase inhibitor antidepressants. Although this hypothesis has enjoyed considerable support-for example, the efficacy of selective serotonin reuptake inhibitors (SSRIs) in the treatment of depression and the loss of clinical efficacy of SSRIs in tryptophan-depleted patients (Nemeroff, 1998; Hirschfeld, 2000) -it does not provide an adequate explanation for the 2 to 3 -week lag period from initiation of drug treatment to the clinical appearance of the therapeutic effects of antidepressant drugs. Another challenge to this hypothesis came from

\footnotetext{
*Correspondence: X-M Li, Neuropsychiatric Research Unit, 103 Wiggins Road, Saskatoon, SK, Canada S7N 5E4. Tel: + I-306-9664438, Fax: + I-306-966-8830, E-mail: xin-min.li@usask.ca

Received 27 February 2002; revised 3 June 2002; accepted 5 June 2002
}

observations that monoamine depletion does not produce depressive symptoms in healthy individuals (Goodwin et al, 1972; Jesberger and Richardson, 1985; Richardson and Jesberger, 1986; Vaidya and Duman, 2001). Subsequent hypotheses suggesting that neuronal plasticity (ie the adaptation of neuronal systems following chronic exposure to antidepressant drugs) underlies their therapeutic actions have directed research to study the neurochemical effects of chronic rather than acute antidepressant treatments.

There is increasing evidence suggesting cellular and molecular adaptations at several levels of brain neurons in response to antidepressant treatment. It has been reported that antidepressant drug treatment blocks the stressinduced atrophy of CA3 pyramidal cells (Watanabe et al, 1992; Duman et al, 1999) and increases neurogenesis of hippocampal granule cells (Malberg et al, 2000). Chronic antidepressant treatment has been demonstrated to upregulate the cAMP response element-mediated (CREmediated) gene expression in the rat cortex and hippocampus (Thome et al, 2000), and to upregulate the expression of the cAMP response element-binding protein (CREB) in both rodents and humans (Nibuya et al, 1996; Dowlatshahi et al, 1998). CREB upregulation may activate downstream targets such as brain-derived neurotrophic factor (BDNF) and tyrosine kinase receptor type B (trkB) 
after antidepressant treatment (Nibuya et al, 1996). Infusion of BDNF into the midbrain (Siuciak et al, 1997) or hippocampus (Shirayama et al, 2002) produces antidepressant-like effect in two animal models of depression: the forced swim test and the learned helplessness paradigm. While these findings support the hypothesis of a role for BDNF in the therapeutic actions of antidepressant treatments, additional chronic studies of clinically effective antidepressant agents are required to further this hypothesis.

A neuroprotective role for $\mathrm{Bcl}-2$ has been established (Jacobson and Raff, 1995; Merry and Korsmeyer, 1997), and it has been demonstrated that $\mathrm{Bcl}-2$ promotes neuronal regeneration in the mammalian central nervous system (Chen et al, 1997). Chronic treatment of rats with two structurally dissimilar mood-stabilizing agents, lithium and valproate, robustly increases Bcl-2 levels in the frontal cortex and markedly increases the number of Bcl-2 immunoreactive cells in frontal cortex layers 2 and 3 (Chen et al, 1999). These findings raise the question: does chronic antidepressant drug treatment have a similar effect on the expression of Bcl-2 protein in hippocampal neurons?

Superoxide dismutases (SODs) are a family of metalloenzymes that catalyze the dismutation of the superoxide anion radical $\left(\mathrm{O}_{2}^{-}\right)$to hydrogen peroxide $\left(\mathrm{H}_{2} \mathrm{O}_{2}\right)$, which in turn is reduced to water by catalase or peroxidases. Copperzinc SOD exerts a protective action against brain injury and neuronal death both in vitro and in vivo (Imaizumi et al, 1990; Uyama et al, 1992; Greenlund et al, 1995). Altered Cu/ $\mathrm{Zn}$-SOD activity has also been implicated in neurodegenerative conditions such as Parkinson's disease (Saggu et al, 1989; Nishiyama et al, 1995). Previous work in our laboratory found that the expression of the SOD gene in PC12 cells could be upregulated by olanzapine, amitriptyline, or venlafaxine ( $\mathrm{Li}$ et $a l, 1998,2000)$. The role of $\mathrm{Cu} / \mathrm{Zn}$ SOD in the pathophysiology of depression and in the therapeutic actions of chronic antidepressant treatments, however, has not yet been investigated.

Our first objective in the present study was to determine whether the chronic administration of amitriptyline (a classic tricyclic antidepressant) or venlafaxine (a newer serotonergic/noradrenergic reuptake inhibitor antidepressant) alters the immunohistochemical staining of BDNF in the hippocampus, the brain area showing the highest level of BDNF expression (Phillips et al, 1990). Our second objective was to examine the effects of chronic amitriptyline or venlafaxine on the expression of $\mathrm{Bcl}-2$ and $\mathrm{Cu} / \mathrm{Zn}$ SOD in hippocampal neurons. In addition, each of the drugs was tested in two doses ( 5 and $10 \mathrm{mg} / \mathrm{kg}$ ), to see if dose-related differences in the expression of the neuroprotective proteins in hippocampal neurons might help to resolve the conflicting data reported by other investigators in the field.

\section{MATERIALS AND METHODS}

All procedures with animals were performed in accordance with the guidelines established by the Canadian Council on Animal Care and were approved by the University of Saskatchewan Animal Care Committee.

\section{Animals and Treatment Paradigms}

A total of 30 adult male Sprague-Dawley rats (200-225 g; Charles River, St Constant, PQ) were used in this study. The rats were housed two per cage and maintained on a 12-h light/12-h dark cycle with food and water freely available. After 1 week of acclimatization, the rats were subjected to the chronic administration of sterilized saline $(n=10)$, amitriptyline $(n=10)$, or venlafaxine $(n=10)$ once daily for 21 consecutive days via intraperitoneal (i.p.) injection. The amitriptyline and venlafaxine solutions were freshly prepared in sterilized saline. The volume of the injected solutions was $1.0 \mathrm{ml} / \mathrm{kg}$. Both amitriptyline and venlafaxine were administered at two doses, 5 or $10 \mathrm{mg} / \mathrm{kg}(n=5$ for each dose); these doses have been widely used in animal studies (Bodnoff et al, 1989; Ferretti et al, 1995; Gur et al, 1999). Over the course of the experiment, the rats were weighed every three days.

The rats were deeply anesthetized with chloral hydrate $(400 \mathrm{mg} / \mathrm{kg}$, i.p.) $24 \mathrm{~h}$ after the last injection, and were perfused through the ascending aorta with $150-200 \mathrm{ml}$ of $0.1 \mathrm{M}$ phosphate-buffered saline (PBS, $\mathrm{pH}$ 7.4) followed by $250-300 \mathrm{ml}$ of a fixative solution of $4 \%$ paraformaldehyde in PBS. The brains of the rats were removed after perfusion, postfixed for $24 \mathrm{~h}$ in the same fixative, and cryoprotected in $20 \%$ sucrose at $4^{\circ} \mathrm{C}$ for $2-3$ days. Brain tissue blocks were frozen in 2-methylbutane prechilled with dry ice and then stored at $-70^{\circ} \mathrm{C}$ until use.

\section{Immunohistochemistry}

The polyclonal primary antibody for Bcl-2 was purchased from Santa Cruz Biotechnology Inc. (Santa Cruz, CA). According to information provided by the manufacturer, this antibody was raised in rabbits and is specific for the epitope mapping at the amino terminus of human $\mathrm{Bcl}-2$ which is identical to the corresponding mouse sequence, without cross-reactivity with other apoptosis-associated proteins. The antibodies for $\mathrm{BDNF}$ and $\mathrm{Cu} / \mathrm{Zn}$-SOD were purchased from Research Diagnostics, Inc. (Flanders, NJ). According to the manufacturer, both of these antibodies were also raised in rabbits. The antibody for BDNF is specific for BDNF with the epitope mapping at the amino terminus of the mature form of human BDNF (identical to the corresponding mouse sequence) and is nonreactive with NGF, NT-3, or NT-4. The antibody for Cu/Zn-SOD detects an approximately $19-\mathrm{kDa}$ band in rodent tissues corresponding to the apparent molecular weight of $\mathrm{Cu} / \mathrm{Zn}-\mathrm{SOD}$ on immunoblots.

The detection of BDNF, Bcl-2, and Cu/Zn-SOD immunoreactivity was performed on free-floating sections using a conventional avidin-biotin-immunoperoxidase technique modified from published protocols (Kim et al, 2000; Xu et $a l$, 2002). Briefly, sections were pretreated with $0.3 \% \mathrm{H}_{2} \mathrm{O}_{2}$ in methanol for $30 \mathrm{~min}$ to block endogenous peroxidase activity, and then, following washes with PBS, were incubated for $1 \mathrm{~h}$ at room temperature with a blocking solution composed of $5 \%$ normal serum, $1 \%$ BSA, and $1 \%$ Triton X-100 in PBS. Sections were next incubated with one of the primary antibodies at dilutions of 1:1000 (the antibody to BDNF), 1:3000 (the antibody to $\mathrm{Bcl}-2$ ), or $1: 4000$ (the antibody to $\mathrm{Zn} / \mathrm{Cu}-\mathrm{SOD}$ ) in PBS containing $0.5 \%$ Triton X-100 and $1 \%$ normal serum, for $48 \mathrm{~h}$ at $4{ }^{\circ} \mathrm{C}$ followed 
by $2 \mathrm{~h}$ at room temperature. The primary antibodies were localized using Vectastain Elite reagents (Vector Laboratories, Burlingame, CA), and the reaction products were developed using $0.025 \% 3,3^{\prime}$-diaminobenzidine (DAB) as chromogen diluted in Tris-HCl-buffered saline (TBS; 0.05 $\mathrm{M}, \mathrm{pH}$ 7.6) and $0.03 \% \mathrm{H}_{2} \mathrm{O}_{2}$ as substrate. Immunohistochemical controls were performed as above except for the omission of the primary antibodies. No positive immunostaining was found in any controls.

\section{Densitometric Analysis}

Quantitative image analysis was performed using the Zeiss Axioskop microscope equipped with a $\times 6.3$ objective lens, a stabilized light source, and an interference filter $(546 \mathrm{~nm})$. Images were captured by a Sony RGB color camera and digitized on a monitor into $512 \times 512$ pixels, wherein the gray scales were measured and analyzed with a computer software package (Northern Eclipse 5.0; Empix Imaging, Mississauga, ON). For BDNF, measurements were taken in the pyramidal cell layer of Ammon's horn (including CA1 to CA4), and in the granular cell layer of the dentate gyrus. Both of these cell types showed intense BDNF immunostaining. For Bcl-2, measurements were performed in hippocampal mossy fibers, because the particularly intense Bcl-2 immunostaining was confined to these fibers. For $\mathrm{Cu} /$ $\mathrm{Zn}$-SOD, measurements were performed in the granular cell layer of the dentate gyrus because of its moderate immunostaining and ease of measurement. For all measurements, the magnification was $\times 5$. Background values were taken from the corpus callosum, which had very weak immunostaining in all sections.

Optical densities of background and target areas were determined by assigning a numerical value between 0 (black) and 255 (white) to each pixel according to its grayscale value. Furthermore, a percentage difference score (DS) in optical density was calculated according to the following formula (Armitage et al, 1998):

$$
\mathrm{DS}(\%)=\frac{(\text { background gray }- \text { target gray })}{(\text { background gray }+ \text { target gray }) / 2} \times 100
$$

We have calibrated the values of the DS from all rats in each group by using this formula, in which the impact of background has been minimized. In addition, we have taken a series of steps to be certain that the quantitative data of the DS are nonbiased. Brain tissue blocks from each rat were sectioned at $30 \mu \mathrm{m}$, and every other section was collected for immunohistochemical staining. For each tissue block, 60 sections were collected in $0.01 \mathrm{M}$ PBS in six wells of a six-well tissue culture plate. For each well (for a given antibody), sections were selected in the same manner (ie every sixth collected section was placed in the same well). Each well contained a total of 30 sections, representing a control rat and two drug-treated rats. The spatial differences of selected sections from different groups were minimized, in that we used five animals in each group. All of these 30 sections passed through all procedures always in the same conditions, to minimize any differences from immunohistochemical staining itself. Similarly, all conditions were identical for the densitometric analysis.

\section{Statistical Analysis}

Body weight data and the data from the optical densitometry of all three antibodies were subjected to analysis of variance (ANOVA) followed by Newman-Keuls post hoc tests with a significance level of $p<0.05$.

\section{RESULTS}

\section{Weight Gain}

Table 1 shows the body weights. Chronic administration of amitriptyline or venlafaxine did not alter the weight gain of the injected rats over the injection period of 3 weeks, although the high dose of the drugs seemed to attenuate the weight gain of the animals in the last week.

\section{BDNF Immunoreactivity}

In a representative vehicle-injected control rat (Figure 1), the greatest intensity of BDNF immunostaining was seen in the hippocampal pyramidal cell layer and in the dentate granular cell layer, while the neuropil of the hippocampus was immunostained weakly. The photo in Figure $1 \mathrm{~b}$ was from a rat injected with $5 \mathrm{mg} / \mathrm{kg}$ of amitriptyline. The intensity of BDNF immunostaining in all hippocampal subareas of this rat is greater than that of the corresponding subareas of the control (Figure 1a). Comparing Figure 1a with c (from a rat injected with $10 \mathrm{mg} / \mathrm{kg}$ of amitriptyline), no evident difference was observed. In Figure 1d (from a rat

Table I Influence of Chronic Antidepressant Drugs on Weight Gain of Rats

\begin{tabular}{|c|c|c|c|c|c|c|}
\hline \multirow[b]{2}{*}{ Day } & \multicolumn{3}{|c|}{ Amitriptyline } & \multicolumn{3}{|c|}{ Venlafaxine } \\
\hline & Saline & 5 mg/kg & 10 mg/kg & Saline & $5 \mathrm{mg} / \mathrm{kg}$ & 10 mg/kg \\
\hline I & $269.5 \pm 7.5$ & $262.4 \pm 8.3$ & $276.5 \pm 5.2$ & $279.4 \pm 11.9$ & $266.8 \pm 8.2$ & $271.2 \pm 8.1$ \\
\hline 4 & $288.0 \pm 10.6$ & $276.2 \pm 13.6$ & $292.7 \pm 8.0$ & $292.8 \pm 16.1$ & $286.6 \pm 8.1$ & $289.2 \pm 12.0$ \\
\hline 7 & $313.8 \pm 14.3$ & $305.6 \pm 16.5$ & $309.5 \pm 12.9$ & $309.8 \pm 23.4$ & $310.6 \pm 4.0$ & $306.5 \pm 17.6$ \\
\hline 10 & $331.4 \pm 16.6$ & $323.4 \pm 15.1$ & $323.7 \pm 11.6$ & $326.4 \pm 31.0$ & $329.0 \pm 7.4$ & $324.8 \pm 21.7$ \\
\hline 13 & $351.4 \pm 19.9$ & $341.6 \pm 17.5$ & $332.2 \pm 15.6$ & $339.2 \pm 35.5$ & $349.8 \pm 7.7$ & $329.2 \pm 28.8$ \\
\hline 16 & $367.2 \pm 22.0$ & $355.0 \pm 19.7$ & $344.3 \pm 15.4$ & $351.8 \pm 40.0$ & $359.6 \pm 12.6$ & $349.3 \pm 25.8$ \\
\hline 19 & $385.8 \pm 23.0$ & $370.4 \pm 18.7$ & $352.0 \pm 23.2$ & $367.8 \pm 39.7$ & $375.2 \pm 13.6$ & $363.2 \pm 27.3$ \\
\hline 22 & $399.4 \pm 32.2$ & $383.0 \pm 23.0$ & $365.8 \pm 24.4$ & $379.8 \pm 27.7$ & $390.4 \pm 11.9$ & $372.3 \pm 30.9$ \\
\hline
\end{tabular}

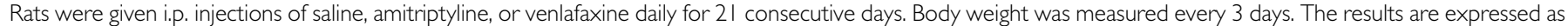
the mean $(g) \pm \operatorname{SD}(n=5)$. 


\section{Dose-related effects of chronic antidepressants}
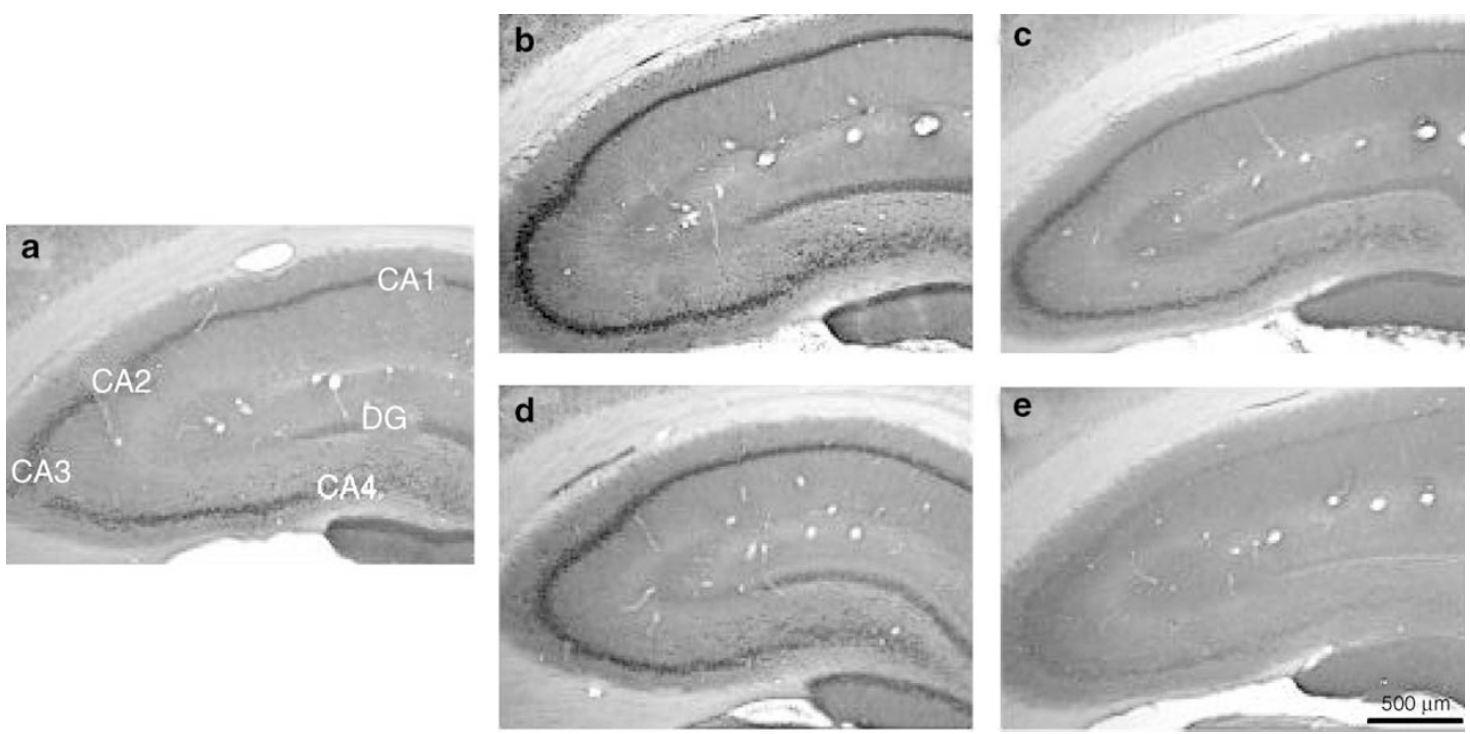

Figure I Effects of the chronic administration of amitriptyline or venlafaxine on BDNF immunoreactivity in hippocampal neurons of rats. (a) The distribution pattern of BDNF immunostaining in the hippocampus from a saline-injected control rat. The greatest intensity of BDNF immunostaining is seen in the hippocampal pyramidal cell layer and in the dentate granular cell layer. The neuropil of the hippocampus is immunostained weakly. (b) Low-dose amitriptyline $(5 \mathrm{mg} / \mathrm{kg})$ increased the intensity of BDNF immunostaining in the hippocampal pyramidal cell layer, throughout CAI to CA4. The increase in the intensity of BDNF immunostaining in the dentate granular cell layer is not as evident as in the pyramidal cell layer. (c) With high-dose amitriptyline (I 0 mg/kg) the intensity of BDNF immunostaining in a rat is comparable to that in the saline-injected control. (d) Low-dose venlafaxine $(5 \mathrm{mg} / \mathrm{kg})$ increased the intensity of BDNF immunostaining. (e) High-dose venlafaxine $(10 \mathrm{mg} / \mathrm{kg})$ decreased the intensity of BDNF mmunostaining in all subareas of the hippocampus.
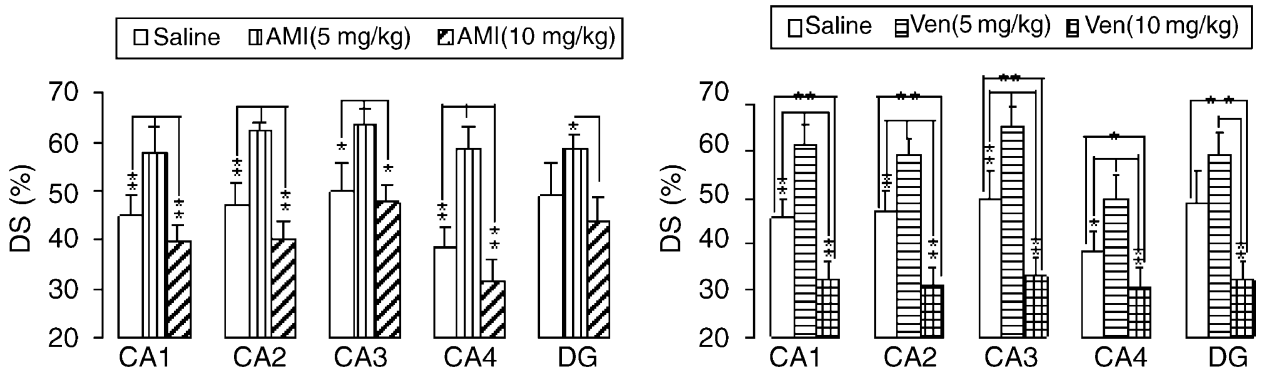

Figure 2 Percentage difference score (DS) in optical density of BDNF immunostaining in different hippocampal subareas of rats injected with saline ( $n=5$ each for two control groups); amitriptyline (AMI) low $(n=5)$ or high $(n=5)$ dose; or venlafaxine (Ven) low $(n=5)$ or high $(n=5)$ dose. Average DS $( \pm$ SEM) is shown for each group in each hippocampal subarea. $* p<0.05$. $* * * 0.01$.
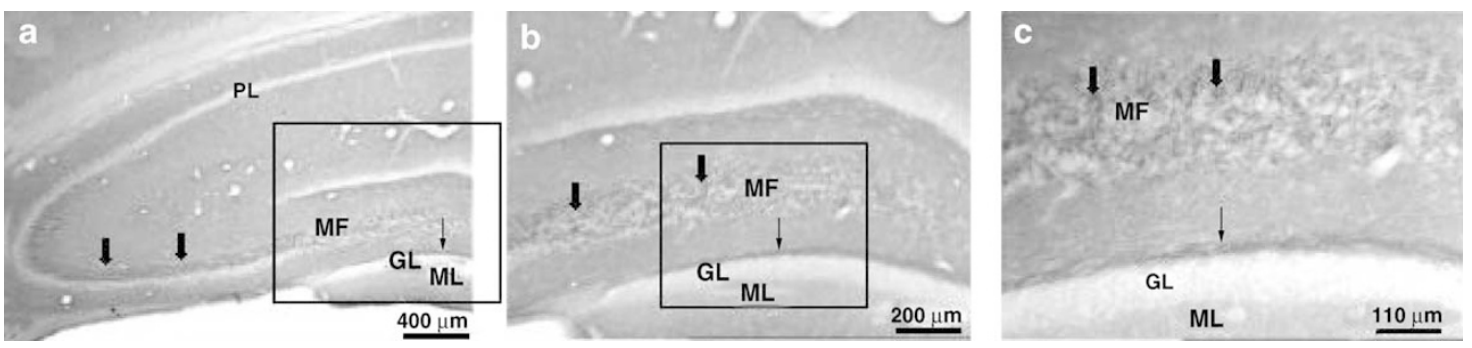

Figure 3 Distribution pattern of Bcl-2 immunoreactivity in the hippocampus of a saline-injected rat. (a) Intense Bcl-2 immunostaining is confined to the hippocampal mossy fibers (MF, indicated by thick arrows). The pyramidal cell layer (PL) and the dentate granular cell layer (GL) are very poorly labeled. The axonal collaterals in the polymorph layer of the dentate gyrus exhibit very dark staining (indicated by a thin arrow). (b) Intense Bcl-2 immunostaining seen in MF and the axonal collaterals of the dentate granular neurons under $\times 10$ magnification. (c) Intense Bcl- 2 immunostaining in MF and the axonal collaterals of the dentate granular neurons is clearly seen at $20 \times$ magnification. 
injected with $5 \mathrm{mg} / \mathrm{kg}$ of venlafaxine) the intensity of the immunostaining in the hippocampal pyramidal cell layer of this rat is greater than that in the control (Figure 1a), and the intensity of immunostaining in the dentate granule cell layer is comparable to that in the control. In Figure 1e (from a rat injected with $10 \mathrm{mg} / \mathrm{kg}$ of venlafaxine), the intensity of BDNF immunostaining in all hippocampal subareas is markedly lower than that in the corresponding subareas of the control.

Calculated percentage difference scores in optical density of BDNF immunostaining in the different groups are displayed in Figure 2. The low dose $(5 \mathrm{mg} / \mathrm{kg})$ of amitriptyline significantly increased the DS values of BDNF immunostaining in CA1 to CA4, but not in the dentate granule cell layer. No significant differences were found between the animals treated with the high dose $(10 \mathrm{mg} / \mathrm{kg})$ of amitriptyline and the control group, while the differences between the low and high doses of the drug-treated animals were significant. The low dose of venlafaxine significantly increased the DS values of BDNF immunostaining in the pyramidal cell layer CA1 to CA4, but not in the dentate granule cell layer. In contrast to amitriptyline, the high dose $(10 \mathrm{mg} / \mathrm{kg})$ of venlafaxine significantly decreased the DS values of BDNF immunostaining in all hippocampal subareas. The differences between the low and high doses of venlafaxine-treated animals are also significant.

\section{Bcl-2 Immunoreactivity}

The pattern of Bcl-2 immunostaining in the hippocampus is shown in Figure 3. Particularly intense Bcl-2 immunostaining was seen only in the hippocampal mossy fibers that occupy the stratum lucidum of hippocampal CA3 (indicated by thick arrows). Cell bodies of pyramidal neurons and the dentate granular neurons were very poorly labeled for Bcl-2, while other layers were moderately stained. The immunostaining in the polymorph layer of dentate gyrus was largely confined to the neuropil, especially to the axonal collaterals (indicated by a thin arrow) of the dentate granular neurons.
At higher magnifications, the intense Bcl-2 immunostaining in the hippocampal mossy fibers, and in the axonal collaterals of dentate granular neurons (Figure $3 b, c$ ), is clearly shown.

Figure 4 shows the effects of the chronic administration of amitriptyline or venlafaxine on the Bcl-2 immunostaining in the mossy fibers. The photo in Figure $4 \mathrm{~b}$ was from a rat injected with $5 \mathrm{mg} / \mathrm{kg}$ of amitriptyline. The intensity of Bcl-2 immunostaining in the mossy fibers of this rat is greater than that of the control (Figure 4a). Comparing Figure 4a with c (from a rat injected with $10 \mathrm{mg} / \mathrm{kg}$ of amitriptyline), no evident difference was observed. In Figure $4 \mathrm{~d}$ (from a rat injected with $5 \mathrm{mg} / \mathrm{kg}$ of venlafaxine), the intensity of the immunostaining is greater than that in the control. In Figure $4 \mathrm{e}$ (from a rat injected with $10 \mathrm{mg} / \mathrm{kg}$ of venlafaxine), the intensity is comparable to that in the control.

Optical density measurements of Bcl-2 immunoreactivity confirmed that the low dose $(5 \mathrm{mg} / \mathrm{kg})$ of amitriptyline $(p<0.05)$ or venlafaxine $(p<0.01)$ increased the DS values of Bcl-2 immunostaining in the hippocampal mossy fibers of rats, but the high dose $(10 \mathrm{mg} / \mathrm{kg})$ of the drugs did not affect these values (Figure 5).

\section{Cu/Zn-SOD Immunoreactivity}

The greatest intensity of the $\mathrm{Cu} / \mathrm{Zn}$-SOD immunostaining was found in small neurons (indicated by arrows in Figure $6 \mathrm{a}, \mathrm{c})$ scattered in all layers of the hippocampus. In the dentate gyrus, the intense $\mathrm{Cu} / \mathrm{Zn}$-SOD positive neurons were seen mainly in the polymorph layer. In the molecular layer of the dentate gyrus, a trilaminar pattern of $\mathrm{Cu} / \mathrm{Zn}$ SOD immunostaining was seen (Figure $6 \mathrm{~b}$ ), with weak labeling in the inner molecular layer (iml), moderate labeling in the middle/outer molecular layer $(\mathrm{m} / \mathrm{o})$, and very light labeling in the stratum lacunosum-moleculare (str l-m). The pyramidal cells were weakly stained; the granular neurons were moderately stained.

Figure 7 shows the effects of the chronic administration of amitriptyline or venlafaxine on the $\mathrm{Cu} / \mathrm{Zn}-\mathrm{SOD}$ immuno-

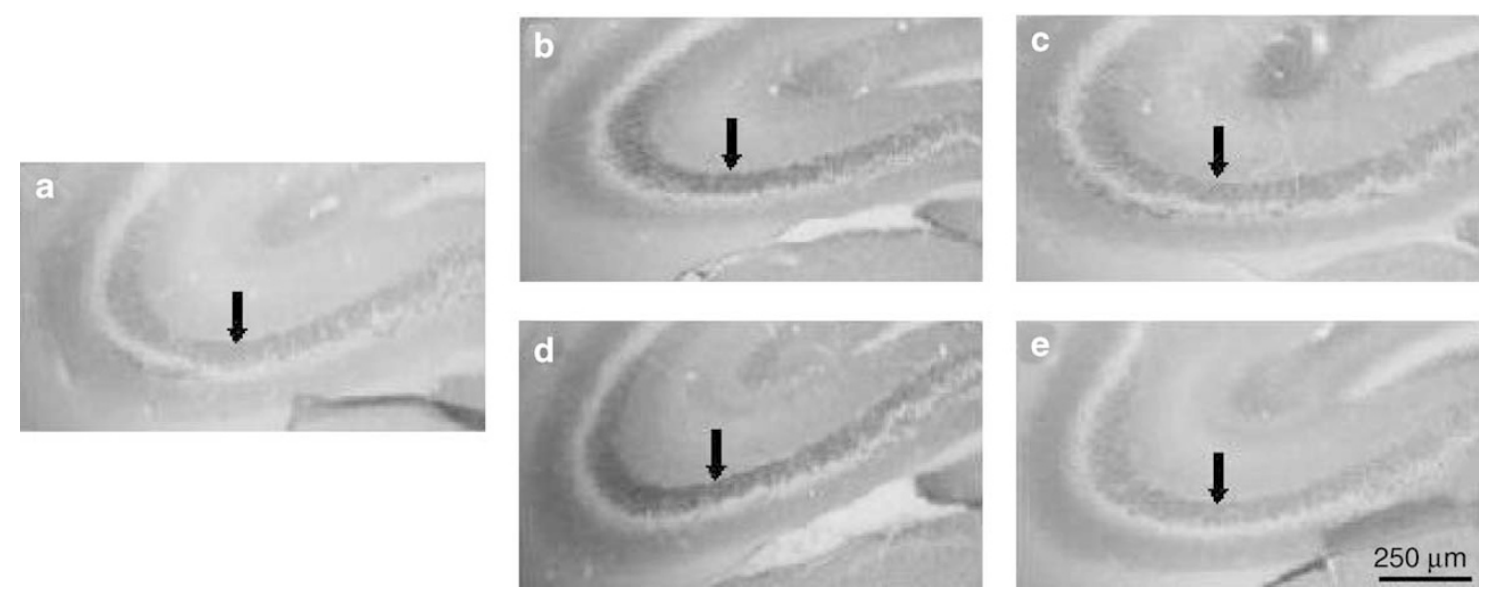

Figure 4 Effects of the chronic administration of amitriptyline or venlafaxine on Bcl-2 immunoreactivity in the hippocampal mossy fibers of rats. (a) Control rat injected with saline. (b) Low-dose $(5 \mathrm{mg} / \mathrm{kg}$ ) amitriptyline increased the intensity of Bcl-2 immunostaining in the mossy fibers. (c) High-dose $(10 \mathrm{mg} / \mathrm{kg})$ amitriptyline did not affect the intensity of $\mathrm{Bcl}-2$ immunostaining in the mossy fibers. (d) Low-dose $(5 \mathrm{mg} / \mathrm{kg})$ venlafaxine increased the intensity of $\mathrm{Bcl}-2$ immunostaining in the mossy fibers. (e) High-dose $(10 \mathrm{mg} / \mathrm{kg}$ ) venlafaxine did not affect the intensity of Bcl-2 immunostaining in the mossy fibers. 

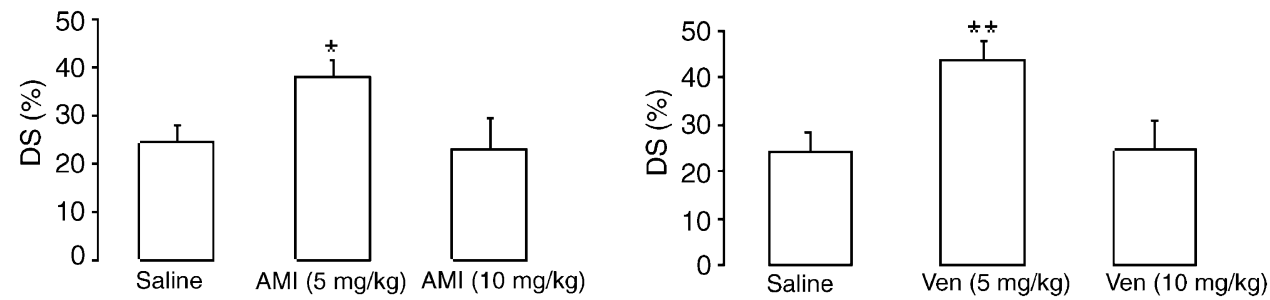

Figure 5 Percentage difference score (DS) in optical density of Bcl-2 immunostaining in the hippocampal mossy fibers of rats injected with saline ( $n=5$ each for two control groups); amitriptyline (AMI) low $(n=5)$ or high $(n=5)$ dose; or venlafaxine (Ven) low $(n=5)$ or high $(n=5)$ dose. Average DS $( \pm$ SEM) is shown for each group. * $p<0.05$, low-dose AMI vs saline control. ** $p<0.0$ l, low-dose Ven vs saline control.
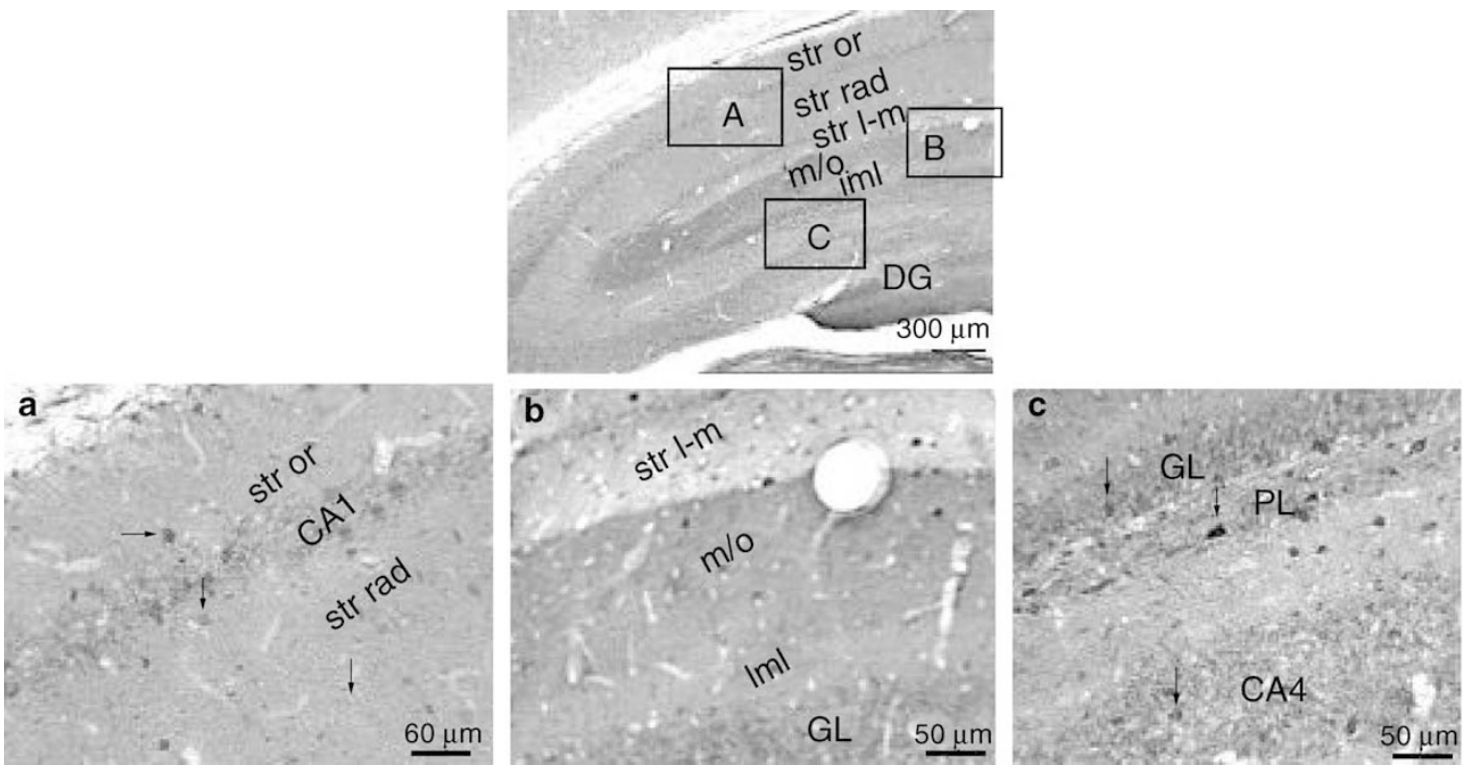

Figure 6 Distribution pattern of Cu/Zn-SOD immunoreactivity in the hippocampus of a saline-injected rat. Top: The greatest intensity of the Cu/Zn-SOD immunostaining is found in small neurons scattered in all layers of the hippocampus. The dentate granular cell layer was moderately immunostained; the pyramidal cell layer was weakly labeled. In the molecular layer of DG, a trilaminar pattern of Cu/Zn-SOD immunostaining is seen, with weak labeling in the inner molecular layer (iml), moderate labeling in the middle/outer molecular layer (m/o), and very light labeling in the stratum lacunosum-moleculare (str I-m). Bottom: (a) Layer CAI. Darkly immunostained neurons are found in stratum oriens (str or) and stratum radiatum (str rad) as indicated by arrows; $\times 20$ magnification. (b) Molecular layer of DG. The specific trilaminar pattern of Cu/Zn-SOD immunostaining in the molecular layer of DG is seen under higher magnification $(\times 20)$. (c) Darkly immunostained interneurons, indicated by arrows, are seen in the polymorph layer of DG at $\times n n$ magnification.

staining in the granular cell layer of the dentate gyrus. The photo in Figure $7 \mathrm{c}$ was from a rat injected with $10 \mathrm{mg} / \mathrm{kg}$ of amitriptyline. The intensity of $\mathrm{Cu} / \mathrm{Zn}-\mathrm{SOD}$ immunostaining in the granular cell layer of the dentate gyrus of this rat is greater than that of the control (Figure 7a). Comparing Figure $7 \mathrm{a}$ with $\mathrm{b}$ (from a rat injected with $5 \mathrm{mg} / \mathrm{kg}$ of amitriptyline), the difference was not evident. In Figure $7 \mathrm{~d}$ (from a rat injected with $5 \mathrm{mg} / \mathrm{kg}$ of venlafaxine), the intensity of the immunostaining is comparable to the control. In Figure $7 \mathrm{e}$ (from a rat injected with $10 \mathrm{mg} / \mathrm{kg}$ of venlafaxine), the intensity is greater than that in the control.

Optical density measurements of $\mathrm{Cu} / \mathrm{Zn}$-SOD immunoreactivity confirmed that the high dose $(10 \mathrm{mg} / \mathrm{kg})$ of amitriptyline $(p<0.05)$ or venlafaxine $(p<0.01)$ increased the DS values of $\mathrm{Cu} / \mathrm{Zn}$-SOD immunostaining in the granule cell layer of rats, but the low dose $(5 \mathrm{mg} / \mathrm{kg})$ of these drugs had no significant effect (Figure 8).

\section{DISCUSSION}

Consistent with the earlier reports of elevated hippocampal BDNF mRNA following chronic, but not acute, administration of the antidepressant drugs tranylcypromine, sertraline, desipramine, mianserin, imipramine, or fluoxetine (Nibuya et al, 1995, 1996), the results of the present study indicate that hippocampal BDNF protein is elevated following chronic administration of the antidepressants amitriptyline or venlafaxine at the low dose $(5 \mathrm{mg} / \mathrm{kg})$. It should be noted that the elevated BDNF mRNA reported by the previous studies was observed both in the hippocampal pyramidal cell layer and the dentate granule cell layer, while in the present study the elevated BDNF immunoreactivity was seen only in the hippocampal pyramidal cell layer. This discrepancy may be due to the different regulation of BDNF mRNA in the different subfields of the hippocampus; it has been reported that chronic electroconvulsive seizures 

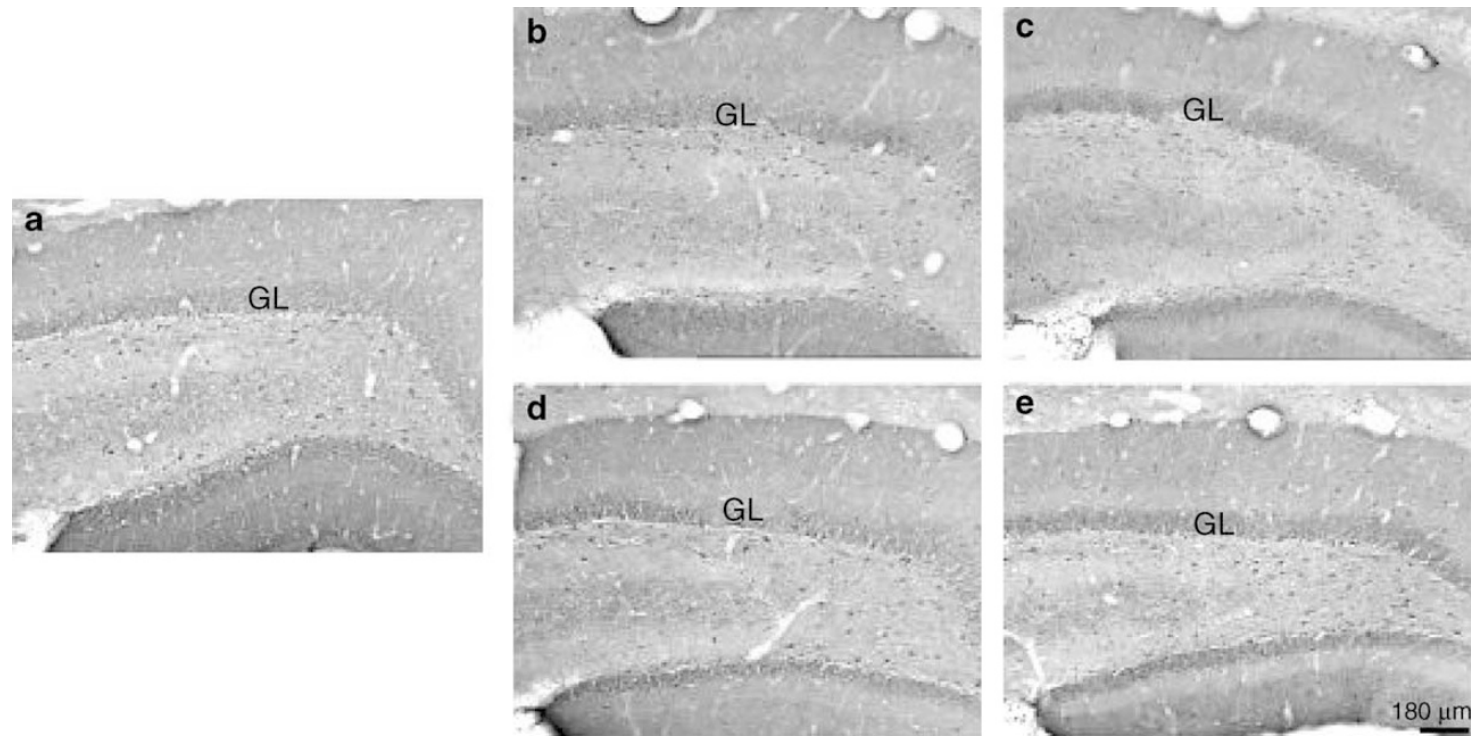

Figure 7 Effects of the chronic administration of amitriptyline or venlafaxine on Cu/Zn-SOD immunoreactivity in the dentate granular cell layer. (a) Control rat injected with saline. (b) Low-dose $(5 \mathrm{mg} / \mathrm{kg}$ ) amitriptyline did not affect the intensity of Cu/Zn-SOD immunostaining. (c) High-dose (IO mg/kg) increased it. (d) Low-dose $(5 \mathrm{mg} / \mathrm{kg})$ venlafaxine did not affect the intensity of immunostaining. (e) High-dose $(10 \mathrm{mg} / \mathrm{kg})$ venlafaxine markedly increased it.
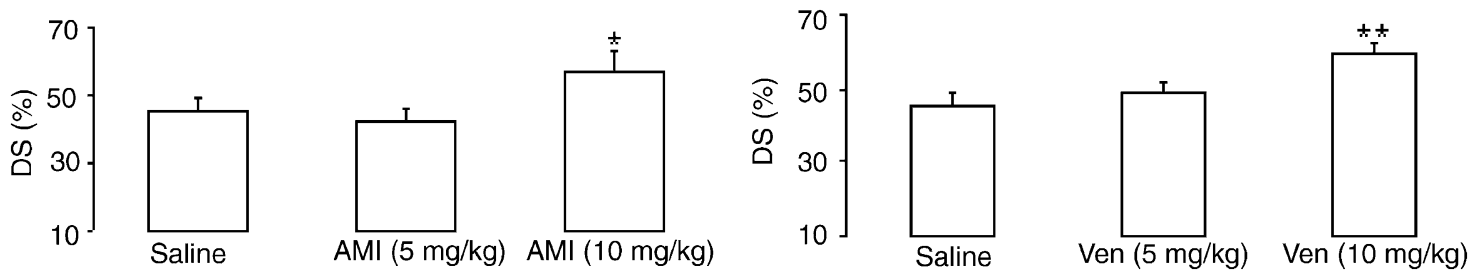

Figure 8 Percentage difference score (DS) in optical density of Cu/Zn-SOD immunostaining in the dentate granule cell layer of rats injected with saline ( $n=5$ each for two control groups); amitriptyline (AMI) low $(n=5)$ or high $(n=5)$ dose; or venlafaxine (Ven) low $(n=5)$ or high $(n=5)$ dose. Average DS ( \pm SEM) is shown for each group. * $p<0.05$, high-dose AMI vs saline control. ** $p<0.0$ l, high-dose Ven vs saline control.

decreased the acute induction of BDNF and trkB mRNA but markedly prolonged their duration in the dentate gyrus granule cell layer, while the seizures increased the acute induction of BDNF and trkB mRNA in CA3 and CA1 pyramidal cell layers (Nibuya et al, 1995).

Our results also suggest that the direction of the BDNF change is related to the dose of the antidepressant drug being given. The increase in the BDNF immunostaining in hippocampal pyramidal cells seen after the $5 \mathrm{mg} / \mathrm{kg}$ dose of either amitriptyline or venlafaxine (Figure 1) was not seen after the high dose. While high-dose amitriptyline did not alter BDNF immunostaining, high-dose venlafaxine actually reduced BDNF immunostaining in hippocampal neurons. This suggests that the high dose of the drugs in this paradigm is excessive and lacks neuroprotective effect on hippocampal neurons. Consistent with this suggestion, at $10 \mathrm{mg} / \mathrm{kg}$ both the drugs increased hippocampal $\mathrm{Cu} / \mathrm{Zn}$ SOD immunostaining (Figure 7). The high dose of the drugs did not, however, affect the weight gain of the animals in the 3 -week injection period (Table 1). Neither were abnormalities found in the animals' general health or demeanor. In fact, the doses used in the present study have been demonstrated to be effective in animal models
(Stockert et al, 1988; Bodnoff et al, 1989; Malatynska et al, 1995; Ferretti et al, 1995; McGrath and Norman 1998; Gur et al, 2002). Although we have not yet determined the causative factors for this paradox, the dose-related effects of the drugs on the BDNF immunostaining in hippocampal neurons may have functional significance and should be explored further.

Amitriptyline and venlafaxine are broad-spectrum antidepressant drugs that share the ability to inhibit the reuptake of both noradrenaline and serotonin from synaptic clefts. The former is a classic tricyclic antidepressant drug that is also a potent antagonist at muscarinic acetylcholine receptors. The latter is a newer antidepressant drug that lacks antimuscarinic actions. It has been suggested that the activation of BDNF may be one of the final steps in a complex chain of intracellular events affected by antidepressant treatments (Duman et al, 1997). The ability of antidepressant interventions to increase the concentration of noradrenaline and serotonin in synapses, and the subsequent downregulation of postsynaptic receptors for these two neurotransmitters, can be accomplished by a variety of mechanisms: inhibition of intracellular metabolism by monoamine oxidase, increased release from the 
presynaptic nerve terminal by downregulation of inhibitory presynaptic autoreceptors, or reduced removal from the synapse by blocking the reuptake transporter. These actions result in the alteration of a wide range of postsynaptic second-messenger systems (Reid and Stewart, 2001) that ultimately alter gene expression. It has long been known that the downregulation of brain $\beta$-noradrenergic receptors follows chronic, but not acute, exposure to antidepressant drugs (Vetulani and Sulser, 1975) and is a common consequence of the chronic administration of all clinically effective antidepressant drug treatments (Jesberger and Richardson, 1985). The functional and mechanistic connections between the ability of chronic antidepressant drugs to downregulate hippocampal $\beta$ adrenergic receptors (Richardson and Tiong, 1999) and to upregulate hippocampal BDNF (the present study) remain to be investigated.

$\mathrm{Bcl}-2$ is a membrane-associated protein with both antiapoptotic and neurotrophic properties (Bernier and Parent, 1998a). The expression of this protein in the brain is induced as part of the cellular response to damage caused by cerebral ischemia (Ferrer et al, 1998), trauma (Nakamura et al, 1999), or oxidative stress (Kaufmann et al, 2001). Within the hippocampus, Bcl-2 immunostaining in mature brains is sparse or absent (Hara et al, 1996; Niwa et al, 1997); however, marked Bcl-2 immunostaining is found in immature brains, during neurogenesis in brains of any age (Bernier and Parent, 1998b); following seizures induced by domoic acid (Ananth et al, 2001) or by kainic acid (Henshall et al, 2001), and after chronic treatment with the antimanic drug lithium (Manji et al, 2000), the antiparkinsonian drugs talipexole or pramipexole (Takata et al, 2000), or the antidepressant drugs amitriptyline or venlafaxine (the present study).

The specific pattern of hippocampal Bcl-2 immunostaining differs among these studies. Bernier and Parent (1998b) observed Bcl-2 in the granule cell layer of the dentate gyrus in both immature and mature primate brains; Takata $e t$ al, (2000) noted elevated Bcl-2 immunostaining in hippocampal dendritic processes; and in the present study we found increased Bcl-2 immunostaining in the hippocampal mossy fibers. These differences may result from different experimental conditions, such as tissue fixation, tissue processing subsequent to fixation, or other aspects of the immunohistochemical protocol (Sofroniew et al, 1983). Since repeated electroconvulsive stimulation, but not antidepressant drug treatment, induces mossy fiber sprouting in the rat hippocampus (Gombos et al, 1999; Lamont et al, 2001), we suggest that the increased Bcl-2 immunostaining in hippocampal mossy fibers by the chronic administration of antidepressant drugs observed in the present study results from the upregulation of the $\mathrm{Bcl}-2$ expression rather than from the sprouting of the mossy fibers. This is not conflicting with the significant increase of BDNF immunostaining by $5 \mathrm{mg} / \mathrm{kg}$ of the antidepressants, in view of the report that transgenic mice overexpressing BDNF do not show hippocampal mossy fiber sprouting (Qiao et al, 2001). No matter what the interplay between BDNF and $\mathrm{Bcl}-2$ expression, $\mathrm{Bcl}-2$ is a valuable marker that targets the hippocampal mossy fibers and BDNF immunostaining labels the cell bodies of hippocampal neurons.
Consider the changes in the expression of $\mathrm{Cu} / \mathrm{Zn}$-SOD compared with BDNF in hippocampal neurons following chronic exposure to the antidepressants. The low dose of both amitriptyline and venlafaxine increased the BDNF immunostaining in hippocampal neurons but had no effect on $\mathrm{Cu} / \mathrm{Zn}$-SOD. This suggests that the expression of BDNF is more sensitive to the drugs than is the expression of $\mathrm{Cu} /$ $\mathrm{Zn}$-SOD. With the high dose, however, both drugs increased the $\mathrm{Cu} / \mathrm{Zn}$-SOD immunostaining in hippocampal neurons, whereas high-dose venlafaxine decreased the BDNF immunostaining in the same neurons but high-dose amitriptyline had no effect. This suggests that the increased expression of $\mathrm{Cu} / \mathrm{Zn}$-SOD may be the response of hippocampal neurons to the high doses of the antidepressants, doses that may be in the cytotoxic range. The immunostaining of $\mathrm{Cu} / \mathrm{Zn}-\mathrm{SOD}$ in the pyramidal cell layer is weak; in the granular cell layer of the dentate gyrus, it is moderately intense. This indicates that dentate gyrus granule cells have a greater ability to express $\mathrm{Cu} / \mathrm{Zn}$-SOD in response to chronic exposure to the antidepressants.

\section{ACKNOWLEDGEMENTS}

This work was supported by Saskatchewan Health, Canadian Psychiatric Research Foundation, Schizophrenia Research Society of Saskatchewan, and a CIHR/Rx \& D Postdoctoral Fellowship (HX). The authors thank Drs. Sergey Fedoroff, Kurt Gibson, and Peter Yu for their helpful comments on this manuscript.

\section{REFERENCES}

Ananth C, Thameem DS, Gopalakrishnakone P, Kaur C (2001). Domoic acid-induced neuronal damage in the rat hippocampus: changes in apoptosis related genes (Bcl-2, Bax, caspase-3) and microglia response. J Neurosci Res 66: 177-190.

Armitage LL, Mohapei P, Jenkins EM, Hannesson DK, Corcoran ME (1998). Dissociation between mossy fiber sprouting and rapid kindling with low-frequency stimulation of the amygdala. Brain Res 781: 37-44.

Bernier PA, Parent A (1998a). The anti-apoptosis bcl-2 protooncogene is preferentially expressed in limbic structures of the primate brain. Neuroscience 82: 635-640.

Bernier PA, Parent A (1998b). Bcl-2 protein as a marker of neuronal immaturity in postnatal primate brain. J Neurosci 18: 2486-2497.

Bodnoff SR, Suranyi-Cadotte B, Quirion R, Meaney MJ (1989). A comparison of the effects of diazepam versus several typical and atypical antidepressant drugs in an animal model of anxiety. Psychopharmacology (Berl) 97: 277-279.

Bunney WE, Davis JM (1965). Norepinephrine in depressive reactions: A review. Arch Gen Psychiatry 13: 483-494.

Chen DF, Schneider GE, Martinou JC, Tonegawa S (1997). Bcl-2 promotes regeneration of severed axons in mammalian CNS. Nature 385: 434-439.

Chen G, Zeng WZ, Yuan PX, Huang LD, Jiang YM, Zhao ZH et al (1999). The mood-stabilizing agents lithium and valproate robustly increase the levels of the neuroprotective protein bcl2 in the CNS. J Neurochem 72: 879-882.

Dowlatshahi D, MacQueen GM, Wang JF, Young LT (1998). Increased temporal cortex CREB concentrations and antidepressant treatment in major depression. Lancet 352: 1754-1755. 
Duman RS, Heninger GR, Nestler EJ (1997). A molecular and cellular theory of depression. Arch Gen Psychiatry 54: 597-606.

Duman RS, Malberg J, Thome J (1999). Neural plasticity to stress and antidepressant treatment. Biol Psychiatry 46: 1181-1191.

Ferrer I, Lopez E, Blanco R, Rivera R, Ballabriga J, Pozas E, Marti E (1998). Bcl-2, Bax, and Bcl-x expression in the CA1 area of the hippocampus following transient forebrain ischemia in the adult gerbil. Exp Brain Res 121: 167-173.

Ferretti C, Blengio M, Gamalero SR, Ghi P (1995). Biochemical and behavior changes induced by acute stress in a chronic variate stress model of depression: the effects of amitriptyline. Eur J Pharmacol 280: 19-26.

Gombos Z, Spiller A, Cottrell GA, Racine RJ, Burnham WM (1999). Mossy fiber sprouting induced by repeated electroconvulsive shock seizures. Brain Res 844: 28-33.

Goodwin FK, Ebert MH, Bunney WE (1972). Mental effects of reserpine in man: A review. In: Shader RI (ed). Psychiatric Complications of Medical Drugs. Raven: New York, pp 73-101.

Greenlund LJS, Deckwerth TL, Johnson EM (1995). Superoxide dismutase delays neuronal apoptosis: a role for reactive oxygen species in programmed cell death. Neuron 14: 303-316.

Gur E, Dremencov E, Lerer B, Newman ME (1999). Venlafaxine: acute and chronic effects on 5-hydroxytryptamine levels in rat brain in vivo. Eur J Pharmacol 372: 17-24.

Gur E, Dremencov E, Van De Kar LD, Lerer B, Newman ME (2002). Effects of chronically administered venlafaxine on 5-HT receptor activity in rat hippocampus and hypothalamus. Eur J Pharmacol 436: $57-65$.

Hara A, Hirose Y, Wang A, Yoshimi N, Tanaka T, Mori H (1996). Localization of $\mathrm{Bax}$ and $\mathrm{Bcl}-2$ proteins, regulators of programmed cell death, in the human central nervous system. Virchows Arch 429: 249-253.

Henshall DC, Skradski SL, Lan IQ, Ren T, Simon RP (2001). Increased Bcl-w expression following focally evoked limbic seizures in the rat. Neurosci Lett 305: 153-156.

Hirschfeld RM (2000). History and evolution of the monoamine hypothesis of depression. J Clin Psychiatry 61(Suppl 6) 4-6.

Imaizumi S, Woolworth V, Fishman RA, Chan PH (1990). Liposome-entrapped super-oxide dismutase reduces cerebral infarction in cerebral ischemia in rats. Stroke 21: 1312-1317.

Jacobson MD, Raff M (1995). Programmed cell death and Bcl-2 protection in very low oxygen. Nature 374: 814-816.

Jesberger JA, Richardson JS (1985). Neurochemical aspects of depression: The past and the future? Int J Neurosci 27: 19-47.

Kaufmann JA, Bickford PC, Taglialatela G (2001). Oxidative-stressdependent up-regulation of $\mathrm{Bcl}-2$ expression in the central nervous system of aged Fisher-344 rats. J Neurochem 76: 1099-1108.

Kim HC, Bing G, Jhoo WK, Ko KH, Kim WK, Suh JH et al (2000). Changes of hippocampal $\mathrm{Cu} / \mathrm{Zn}$-superoxide dismutase after kainate treatment in the rat. Brain Res 853: 215-226.

Lamont SR, Paulls A, Stewart CA (2001). Repeated electroconvulsive stimulation, but not antidepressant drugs, induces mossy fiber sprouting in the rat hippocampus. Brain Res 893: 53-58.

Li XM, Juorio AV, Qi J, Boulton AA (1998). L-deprenyl potentiates NGF-induced changes in superoxide dismutase mRNA in PC12 cells. J Neurosci Res 53: 235-238.

Li XM, Chlan-Fourney J, Juorio AV, Bennett VL, Shrikhande S, Bowen RC (2000). Antidepressants upregulate messenger RNA levels of the neuroprotective enzyme superoxide dismutase (SOD1). J Psychiatry Neurosci 25: 43-47.

Malberg J, Eisch A, Nestler E, Duman RS (2000). Chronic antidepressant treatment increases neurogenesis in adult rat hippocampus. J Neurosci 20: 9104-9110.

Malatynska E, Leon ID, Allen D, Yamamura HI (1995). Effects of amitriptyline on GABA-stimulated ${ }^{36} \mathrm{Cl}$ uptake in relation to a behavioral model of depression. Brain Res Bull 37: 53-59.

Manji HK, Moore GJ, Chen G (2000). Lithium up-regulates the cytoprotective protein $\mathrm{Bcl}-2$ in the $\mathrm{CNS}$ in vivo: A role for neurotrophic and neuroprotective effects in manic depressive illness. J Clin Psychiatry 6(Suppl 9) 82-96.

McGrath C, Norman TR (1998). The effect of venlafaxine treatment on the behavioral and neurochemical changes in the olfactory bulbectomised rat. Psychopharmacology (Berl) 136: 394-401.

Merry DE, Korsmeyer SJ (1997). Bcl-2 gene family in the nervous system. Annu Rev Neurosci 20: 245-267.

Nakamura M, Raghupathi R, Merry DE, Scherbel U, Saatman KE, McIntosh TK (1999). Overexpression of Bcl-2 is neuroprotective after experimental brain injury in transgenic mice. J Comp Neurol 412: 681-692.

Nemeroff CB (1998). Psychopharmacology of affective disorders in the 21st century. Biol Psychiatry 44: 517-525.

Nibuya M, Morinobu S, Duman RS (1995). Regulation of BDNF and trkB mRNA in rat brain by chronic electroconvulsive seizure and antidepressant drug treatments. J Neurosci 15: 75397547.

Nibuya M, Nestler EJ, Duman RS (1996). Chronic antidepressant administration increases the expression of cAMP response element binding protein (CREB) in the rat hippocampus. $J$ Neurosci 16: 2365-2372.

Nishiyama K, Murayama S, Shimizu J, Ohya Y, Kwak S, Asayama K et al (1995). Cu/Zn superoxide dismutase-like immunoreactivity is present in Lewy bodies from Parkinson disease: A light and electron microscopic immunocytochemical study. Acta Neuropathol (Berl) 89: 471-474.

Niwa M, Hara A, Iwai T, Sassa T, Mori H, Uematsu T (1997). Expression of Bax and Bcl-2 protein in the gerbil hippocampus following transient forebrain ischemia and its modification by phencyclidine. Neurol Res 19: 629-633.

Phillips HS, Hains JM, Laramee GR, Rosenthal A, Winslow JW (1990). Widespread expression of BDNF but not NT-3 by target areas of basal forebrain cholinergic neurons. Science 250: 290294.

Qiao X, Suri C, Knusel B, Noebels JL (2001). Absence of hippocampal mossy fiber sprouting in transgenic mice overexpressing brain-derived neurotrophic factor. J Neurosci Res 64: 268-276.

Reid IC, Stewart CA (2001). How antidepressants work. $\mathrm{Br} J$ Psychiatry 178: 299-303.

Richardson JS, Jesberger JA (1986). Models for the experimental analysis of depression. Acta Psychiatr Belg 86: 733-747.

Richardson JS, Tiong AK (1999). Amygdaloid and hippocampal $\beta$ -adrenoceptors in the olfactory bulbectomy syndrome: Effects of desipramine. Ann NY Acad Sci 877: 764-768.

Saggu H, Cooksey J, Dexter D, Wells FR, Lees A, Jenner P, Marsden CD (1989). A selective increase in particulate superoxide dismutase activity in parkinsonian substantia nigra. J Neurochem 53: 692-697.

Schildkraut JJ (1965). The catecholamine hypothesis of affective disorders: A review of supportive evidence. Am J Psychiatry 122: 509-522.

Shirayama Y, Chen ACH, Nakagawa S, Russell DS, Duman RS (2002). Brain-derived neurotrophic factor produces antidepressant effects in behavioral models of depression. J Neurosci 22: 3251-3261.

Siuciak JA, Lewis DR, Wiegand SJ, Lindsay RM (1997). Antidepressant-like effect of brain-derived neurotrophic factor (BDNF). Pharmacol Biochem Behav 56: 131-137.

Sofroniew MF, Couture R, Cuello AC (1983). Immunocytochemistry: Preparation of antibodies and staining specificity. In: Björklund A, Hökfelt T (eds). Methods in Chemical Neuroanatomy. Elsevier: New York, pp 210-227.

Stockert M, Serra J, Robertis ED (1988). Effect of olfactory bulbectomy and chronic amitriptyline treatment in rats: ${ }^{3} \mathrm{H}-$ imipramine binding and behavioral analysis by swimming and open field tests. Pharmacol Biochem Behav 29: 681-686. 
Takata K, Kitamura Y, Kakimura J, Kohno Y, Taniguchi T (2000). Increase of Bcl-2 protein in neuronal dendritic processes of cerebral cortex and hippocampus by the antiparkinsonian drugs, talipexole and pramipexole. Brain Res 872: 236-241.

Thome J, Sakai N, Shin K, Steffen C, Zhang YJ, Impey S, Storm D, Duman RS (2000). cAMP response element-mediated gene transcription is upregulated by chronic antidepressant treatment. J Neurosci 20: 4030-4036.

Uyama O, Matsuyama T, Michishita H, Nakamura H, Sugita M (1992). Protective effects of human recombinant superoxide dismutase on transient ischemic injury of CA1 neurons in gerbils. Stroke 23: 75-81.
Vaidya VA, Duman RS (2001). Depression: Emerging insights from neurobiology. Br Med Bull 57: 61-79.

Vetulani J, Sulser F (1975). Action of various antidepressant treatments reduces reactivity of noradrenergic cyclic AMPgenerating system in limbic forebrain. Nature 257: 495-496.

Watanabe Y, Gould E, Daniels DC, Cameron H, McEwen BS (1992). Tianeptine attenuates stress-induced morphological changes in the hippocampus. Eur J Pharmacol 222: 157-162.

Xu H, Qing H, Lu W, Keegan D, Richardson JS, Chlan-Fourney J, Li XM (2002). Quetiapine attenuates the immobilization stressinduced decrease of brain-derived neurotrophic factor expression in rat hippocampus. Neurosci Lett 321: 65-68. 